\title{
DEVELOPMENT OF A MATHEMATICAL MODEL OF THE TROLLEYBUS STEERING SYSTEM USING A ROLLING ROTOR SWITCHED RELUCTANCE MOTOR
}

\author{
Tatyana Pavlenko \\ Department of Electric Transport ${ }^{1}$ \\ Oleksandr Petrenko \\ Department of Electric Transport ${ }^{1}$ \\ Viacheslav Shavkun $\bowtie$ \\ Department of Electric Transport ${ }^{1}$ \\ vm.shavkun@gmail.com \\ Ivan Aharkov \\ Department of Electric Transport ${ }^{1}$ \\ ${ }^{1}$ O. M. Beketov National University of Urban Economy in Kharkiv \\ 17 Marshala Bazhanova str., Kharkiv, Ukraine, 61002
}

$\triangle$ Corresponding author

\begin{abstract}
An important part of the overall task of social and economic development of many developed countries is the creation of a unique transport infrastructure or improvement of transport services for the population.

The cumulative solution to many problems is to improve the quality and reliability of elements and equipment in any vehicle design. This determines its efficient operation and the safety of passengers.

A common urban electric transport in megacities is a trolleybus, the reliability of which depends on individual components and assemblies, power supply systems and traffic control.

But this type of transport requires modern scientific and technical solutions for the design of individual components and assemblies, for example, steering, which is directly related to the safe and comfortable transportation of passengers.

An innovative technical solution has been proposed that will increase the energy efficiency of the trolleybus steering system through the use of an electric power steering based on a rolling rotor electric motor. The analysis of the design is carried out and the principle of control of the rolling rotor motor is determined. Functional diagrams of the components of the trolleybus steering system with an electric power steering based on a rolling rotor motor are developed. The electromagnetic and mechanical connections of the motor with the rolling rotor are determined and mathematically described. Factors affecting the steering system when turning the steered wheels are reasoned. A mathematical model of a trolleybus steering system with an electric booster based on an electric rolling rotor motor has been developed. The mathematical model is based on the differential equations of the electrical and mechanical parts. Algebraic equations were used to characterize the electromagnetic connections of the rolling rotor motor. The proposed solution will allow simulating dynamic processes in the trolleybus steering system and evaluating the results. Determination of the efficiency of the steering system was carried out by comparative analysis of the following factors: the control action created by the driver, the condition of the road surface, dynamic and transient electromechanical processes of the system, and the like.
\end{abstract}

Keywords: trolleybus, steering, hydraulic booster, rolling rotor motor.

DOI: $10.21303 / 2461-4262.2021 .001938$

\section{Introduction}

In the modern world, the design of the rolling stock of urban electric transport, in particular trolleybuses, is constantly being improved. The operating experience and research of many foreign and domestic scientists are aimed at the development and implementation of technologies for more effective modernization of elements and systems of trolley buses. This contributes to the efficiency of the structure, increases the comfort and safety of passenger transportation.

This approach provides a reduction in energy and technological costs for the production of rolling stock, operation and repair of the necessary elements and assemblies. 
One of these scientific and technical areas is the improvement of the trolleybus steering system. Layout solutions and operational properties of the rolling stock depend on its design. The indicators of operational efficiency include: stability and controllability of wheels while driving, placement of a traction motor, high maintainability, energy efficiency and energy intensity of mechanisms, and the like.

The development and modernization of new structural elements of rolling stock requires a deep study of the dynamic processes that occur in electrical and mechanical units and systems and affect the behavior of each other.

Investigations related to field experiments increase financial costs, development time, and sometimes do not allow a comprehensive analysis of the processes of the system under study.

In such cases, it is advisable to use simulation methods. This is especially important when studying the parameters of unconventional elements of the structure of rolling stock. Such a method was used in the work to study the parameters of a rolling rotor motor in the steering system of a trolleybus.

Modern trolleybus steering is a combination of mechanisms that ensure the direction of its movement. The main control elements are the steering gear, pneumatic or hydraulic power steering, steering gear and follow-up systems for turning on the pneumatic power steering [1-5].

On some Ukrainian-made trolleybuses, the steering system uses a ball-type hydraulic booster of the SHVGU-720 type (SPO Radiy, Kirovohrad), which consists of a hydraulic pump, a drive motor, an oil tank with a filter, and low and high pressure pipelines [1]. But such a design of the power steering hydraulic station requires constant maintenance in accordance with the prerequisites: changing the oil and filters, providing free access to the oil tank, pump, motor, etc.

In some designs of trolleybuses, a hydraulic steering system is used, which contains a pressure accumulator, a valve device, a pumping station with a hydraulic tank and a constant fluid supply pump connected to the power steering [2]. However, such a system limits the energy consumption of the accumulator. This leads to a decrease in the reliability and safety of vehicle operation.

In models of trolleybuses of foreign firms, for safe operation, emergency power supply of the power steering motor from accumulator batteries is used. On board the trolleybuses, the hydroelectric power station motors have flywheels. They promote the rotation of the motor after it is turned off, and the continuation of the operation of the hydraulic pump to maintain the required pressure of the hydraulic booster [3, 4]. But this amount of equipment leads to an increase in the overall compartments of the trolleybus and constant driver control over its performance. This affects the safety of passenger transportation.

There are also some technical solutions, for example «Danfoss Hydraulische Len Kings Komponenten» [5], which offers a hydraulic steering mechanism for a vehicle containing a hydraulic steering wheel connected to the control line. Such a system is a hydraulic feedback motor, a differential device, as well as distribution, control and priority devices. All elements are interconnected via springs and have two control lines. The disadvantage of this steering mechanism is the delay in its operation and instability against self-oscillations. The design has increased weight and dimensions and energy losses of power.

In the modern world, the elements of the trolleybus are constantly being improved. This contributes to the efficiency of the structure and increases the comfort and safety of passengers [1-6].

The article presents a new technical solution for the steering system of trolleybuses [7, 8], the energy efficiency of which is achieved by using an electric power steering based on an electric rolling rotor motor.

Modern trolleybuses of different brands have a set of mechanisms that affect their operation and traffic safety. One of the main elements of the trolleybus is the steering mechanism, which provides the direction of travel. The trolleybus steering includes power steering, which has a hydraulic or pneumatic system.

In the works [1-3], the results of studies are given, showing the advantages and disadvantages of using a steering system for trolleybuses with a hydraulic booster. 
For example, the results of studies [1] show the effectiveness of using a ball-hydraulic booster in the steering system. It consists of a hydraulic pump, a drive motor, an oil tank with a filter, and low and high pressure pipelines. But the issue of maintaining such a system in accordance with the mandatory conditions has not been practically resolved. These include: changing the oil and filters, ensuring free access to the pump and motor. The disadvantages are shown to affect the efficiency of the hydraulic booster.

The steering system with a pressure accumulator [2] solves efficiency problems through the use of additional elements: a valve device, a pumping station with a hydraulic tank, and the like. But, as the study showed, the issue of a constant supply of fluid to the pump, which is connected to the power steering, has been improved. The shown solution leads to a decrease in the reliability of the vehicle.

The works [3, 4] show the research results when using a hydraulic booster and powering its motor from storage batteries (SB). Due to the use of flywheels and batteries, the motor continues to rotate after it is turned off. The required hydraulic booster pressure is maintained by the pump. This increases the reliability of the trolleybus steering system. But such a solution requires the use of a significant amount of additional equipment and elements. This leads to an increase in the overall compartments of the trolleybus and constant driver control over the performance of the elements. As a result, the comfortable and safe transportation of passengers is reduced.

An option to reduce the disadvantages of the shown research results can be a solution to the use of a hydraulic steering mechanism, which is connected to the control line [5,6]. A feature of the solution is the presence of a feedback hydraulic motor and some devices (differential, distribution, control, etc.) in the system. All elements are interconnected via springs and have two control lines. But there is a problem of delayed operation of the steering mechanism and instability against self-oscillations. Also, such a steering design has increased weight and dimensions and energy losses of power.

Thus, in the modern world, the trolleybus steering system is constantly being improved. This emphasizes the urgency of the problem and makes it possible to assert the need to determine other ways of vehicle traffic safety and comfortable transportation of passengers.

\section{Materials and methods for the development of a mathematical model of the trolleybus steering system}

The aim of research is to develop a mathematical model of a trolleybus steering system using a steering amplifier based on a rolling rotor motor.

For the aim of research, the following objectives have been set:

- to determine the principle of control of a rolling rotor motor and its electromagnetic and electromechanical connections;

- to develop functional diagrams of the components of the trolleybus steering system with an electric power steering based on a rolling rotor motor;

- to develop a mathematical model of a trolleybus steering system based on a rolling rotor motor.

The city trolleybus has a specific steering design that helps to change the direction of the vehicle. But the steering speed is not fast enough and there is also a lot of effort on the part of the driver. This leads to inconvenience of control and the creation of an emergency.

Improving the trolleybus steering system is to achieve high stability and controllability. This position is possible with increased speeds, simplified drive design, high maintainability, and the like.

To study the transient processes of the trolleybus steering system with an electric power steering based on a rolling rotor motor, a mathematical model has been developed.

The mathematical model is based on the task of improving steering with an electromechanical power steering by using a non-contact multi-pole high-torque rolling rotor motor. The implementation of the mathematical model of the trolleybus steering system is carried out in the Matlab Simulink package.

The use of methods of software simulation of transient processes in the trolleybus steering system contributes to the expansion of functionality, a decrease in the number of underbody equipment nodes and energy consumption. 


\section{Research results of the trolleybus steering system and the development of a mathematical model}

According to the set aim of research and certain objectives, the work presents a mathematical model for studying the parameters of the trolleybus steering system. Due to the use of an electric power steering based on an electric rolling rotor motor, the system has electrical and mechanical parts.

The electrical part includes an electromechanical converter (a rolling rotor motor) and a control system. The mechanical part consists of elements for transmitting torque from the motor to the steering wheels. The block diagram of the electric drive control system as part of the trolleybus steering system is shown in Fig. 1.

The proposed trolleybus steering system has electrical and mechanical parts. The electrical part includes an electromechanical converter (rolling rotor motor) and a control system. The mechanical part consists of elements for transmitting torque from the motor to the steering wheels. The steering system is shown in Fig. 1.

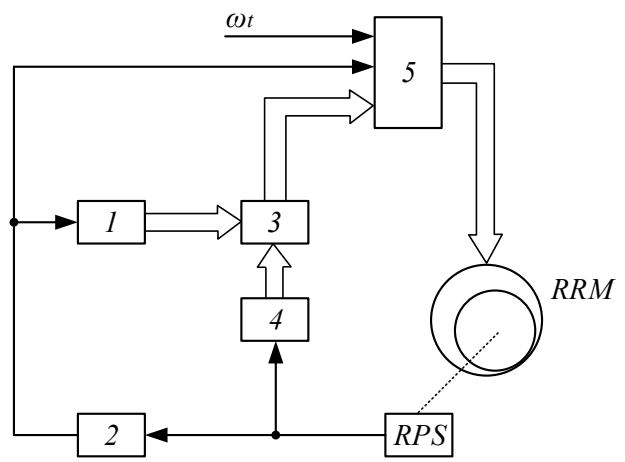

Fig. 1. Block diagram of the electric drive control system as part of the trolleybus steering system: $\omega_{t}-$ signal for setting the rotor speed;

RRM - rolling rotor motor; RPS - rotor position sensor; 1 - block for determining the angles of switching on and off phases; 3 - block for comparing the angle of rotation of the rotor; 2 - block for determining the rotor speed; 4 - block for determining the angle of rotation of the rotor for each phase of the stator; 5 - commutation pulse shaper for each stator phase

The system drive has a control channel for the rotor position angle relative to the stator bore. The signal from the rotor position sensor (RPS) enters unit 2 to determine the synchronous rotor speed. Block 1 calculates the on and off angles for each phase of the rolling rotor motor (RRM). Block 3 compares the on and off angles that come from block 1 with the rotor rotation angles calculated in block 4 relative to each phase of the RPS. In block 5, switching pulses are generated for each phase of the RPS, as well as the synchronous rotor speed is monitored depending on the reference signal.

Electromagnetic processes in the circle of the stator winding depend on the current in the winding and the position of the rotor. The mathematical model is based on the equations of the electrical circuit compiled for each stator coil. The electric circuit of the equivalent motor stator coil is shown in Fig. 2.

The input voltage at the stator terminals is determined by the differential equation:

$$
u=i R+\frac{d \Psi_{(i, \varphi)}}{d t}
$$

where $i$ - stator coil current, A; $\varphi$ - geometric angle of rotation; $\Psi_{(i, \varphi)}-$ flux linkages, Vb.

When developing the model, the following assumptions are made: the magnetic systems of each phase of the motor are identical, eddy currents and hysteresis in the magnetic circuit are not taken into account, the active resistances of the phases are at the level. 
In the general case, the flux linkage for an unsaturated magnetic system is defined as:

$$
\Psi=L \cdot i
$$

where $L$ - inductance of the stator coil, $\mathrm{H}$.

The change in the magnetic field is determined by equations (3), (4):

$$
\begin{gathered}
\frac{d \Psi_{(i, \varphi)}}{d t}=\frac{d\left(i \cdot L_{(i, \varphi)}\right)}{d t} . \\
\frac{d\left(i \cdot L_{(i, \varphi)}\right)}{d t}=\frac{d i}{d t} L_{(i, \varphi)}+i \cdot\left(\frac{\partial L_{(i, \varphi)}}{\partial i} \cdot \frac{d i}{d t}+\frac{\partial L_{(i, \varphi)}}{\partial \varphi} \cdot \frac{d \varphi}{d t}\right)
\end{gathered}
$$

By substituting equation (4) into equation (1), the final equation of the electric circuit of the motor coil is obtained:

$$
\begin{gathered}
u=i R+\frac{d i}{d t}\left(L_{(i, \varphi)}+i \cdot \frac{\partial L_{(i, \varphi)}}{\partial i}\right)+\frac{\partial L_{(i, \varphi)}}{\partial \varphi} \cdot \frac{d \varphi}{d t} \cdot i \\
u=i R+\frac{d i}{d t} \cdot L_{\partial}+K_{E} \cdot \omega_{R},
\end{gathered}
$$

where $L_{\partial}=L_{(i, \varphi)}+i \cdot \partial L_{(i, \varphi)} / \partial i$ - differential inductance, $\mathrm{H} ; K_{E}=\partial L_{(i, \varphi)} / \partial \varphi \cdot i-$ back EMF coefficient; $\omega_{R}=d \varphi / d t-$ angular speed of rotor rotation, $\mathrm{rad} / \mathrm{s}$.

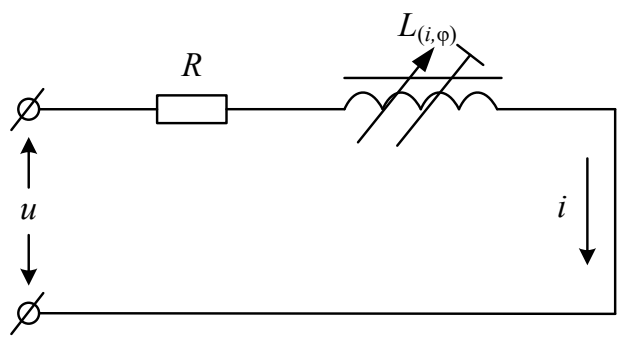

Fig. 2. Electric circuit of the motor stator coil replacement:

$u$ - voltage applied to the stator phase; $R$ - active resistance of the stator coil; $L_{(i, \varphi)}$ - stator coil inductance; $i$ - stator coil current

For the electric circuit of the motor phase with a rolling rotor, a functional diagram is drawn up based on mathematical equations, Fig. 3. The scheme is used for further implementation of the model in software mathematical complexes for simulation modeling.

Mechanical processes of the RRM are presented in the form of a single-mass system (rotational movement of the rotor):

$$
J_{R} \frac{d \omega_{R}}{d t}=M_{e}-M_{r e s}
$$

where $J_{R}$ - reduced moment of inertia of the rotor, $\mathrm{kg} \cdot \mathrm{m}^{2} ; M_{e}-$ moment on the motor shaft, $\mathrm{N} \cdot \mathrm{m}$; $M_{\text {res }}-$ moment of resistance, $\mathrm{N} \cdot \mathrm{m}$.

The moment on the motor shaft with a rolling rotor is defined as $[3,6,9]$ :

$$
M_{e}=\sum F \cdot R_{\text {Rext }},
$$

where $\sum F-$ resulting force of one-sided magnetic attraction, $\mathrm{N}$. 
Angular speed of rotation of the rotor output shaft, $\mathrm{rad} / \mathrm{s}[3,6,9]$ :

$$
\omega_{R}=\omega_{S} \frac{R_{\text {Sint }}-R_{\text {Rext }}}{R_{\text {Rext }}},
$$

where $\omega_{S}-$ synchronous angular speed of rotation of the stator magnetic field, $\mathrm{rad} / \mathrm{s} ; R_{\text {Sint }}-$ inner radius of the stator bore, $\mathrm{m} ; R_{\text {Rext }}-$ outer rotor radius, $\mathrm{m}$.

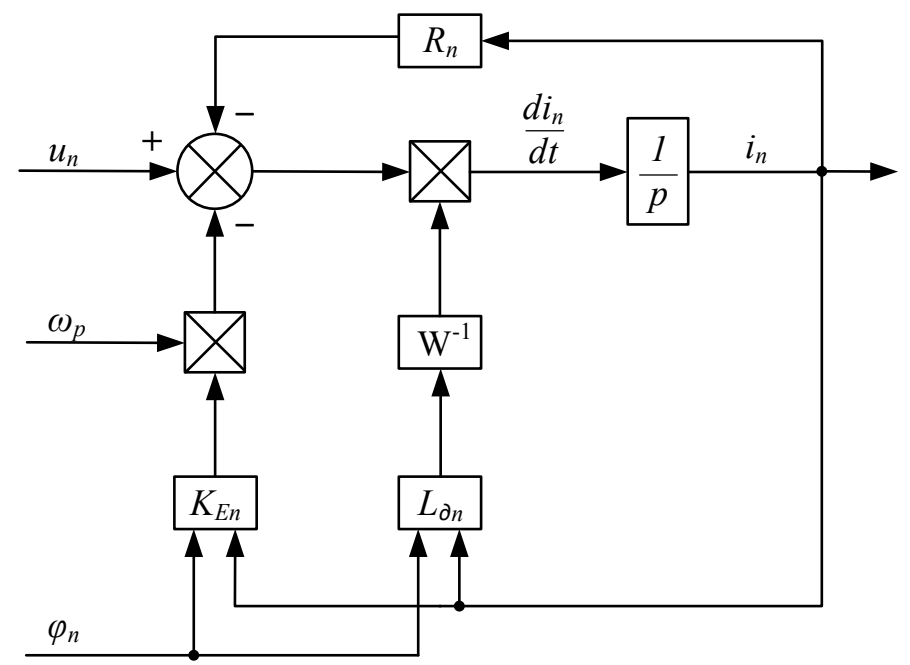

Fig. 3. Functional diagram of a rolling rotor motor phase

The rotor is located eccentrically to the stator. While the motor is running, it performs both translational and rotary motion.

Fig. 4, $\boldsymbol{a}$ shows the effect of magnetic and mechanical forces on the rotor [4]. The rotor axis of rotation is parallel to the horizontal plane. The vector of the magnetic force of the onesided lateral attraction of the poles forms a certain angle $\alpha$ at each moment of time of rotation of the rotor, which passes through the center of the system with a minimum magnetic gap (contact point), Fig. $4, \boldsymbol{b}$ [6]. The resulting magnetic force $F_{\text {mag }}$ can be divided into two components $F_{x}$ and $F_{y}$ (Fig. $\left.4, \boldsymbol{b}\right)[5,6]$. The radial force $F_{x}$ determines the electromagnetic pressure on the bearing surface. The tangential force $F_{y}$ creates an electromagnetic torque [5]. The electromagnetic force that is generated by the stator windings is determined by:

$$
F_{\text {mag }}=\frac{1}{2} i^{2} \frac{d L_{(i, \delta)}}{d \delta}
$$

where $\delta$ - air gap, m.

The centrifugal force (11) and the variable component of gravity (12) also act towards the minimum air gap [4-6].

$$
\begin{gathered}
F_{Z}=m_{R} \omega_{S}^{2} e, \\
F_{G}=m_{R} g,
\end{gathered}
$$

where $m_{R}$ - rotor mass, $\mathrm{kg} ; g$ - acceleration of gravity, $\mathrm{m} / \mathrm{s}^{2} ; e$-rotor eccentricity.

The resulting force is directed in the radial direction. In the case of the horizontal arrangement of the motor shaft, the force is determined $[4,5]$ :

$$
F_{N}=F_{Z}+F_{G} \cos (\varphi)+\sum F_{x}
$$




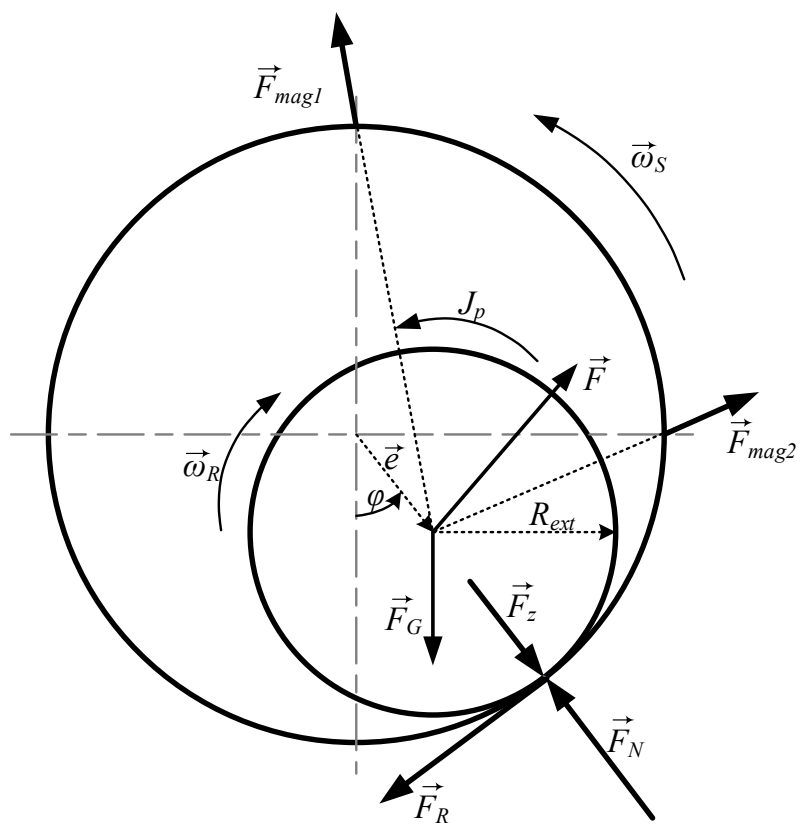

$a$

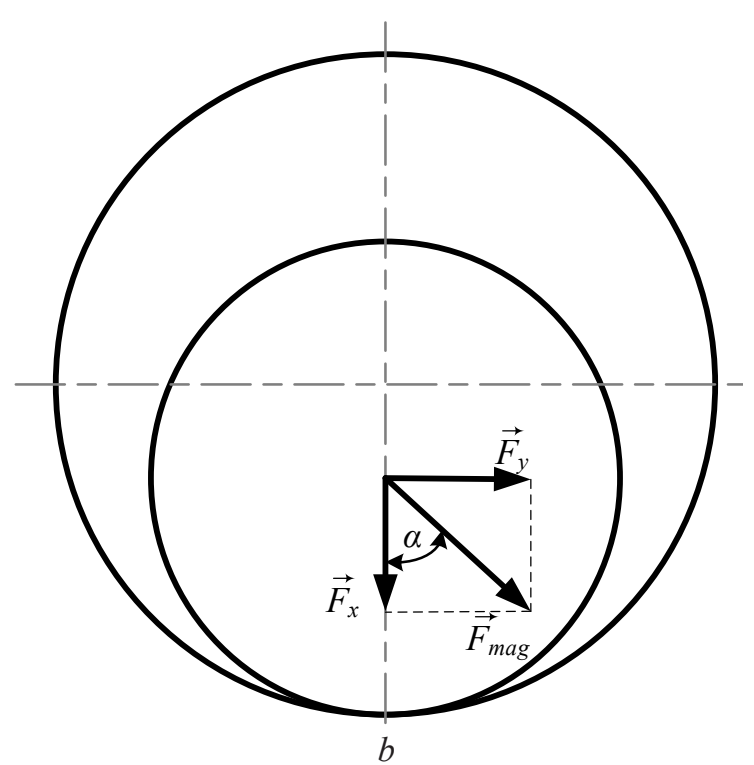

Fig. 4. Distribution of the forces acting on the rotor in rolling rotor motor:

$a$-influence of magnetic and mechanical forces on the rotor when the axis of rotation is parallel to the horizontal plane; $b$-components of the magnetic force vector; $\omega_{R}$ - angular speed of the rotor rotation; $\omega_{S}$ - angular speed of rotation of the stator field; $R_{\text {Rext }}$ - outer rotor radius; $J_{R}$ - moment of inertia of the rotor; $F_{N}$ - force of normal reaction; $F_{Z}$-centrifugal force; $F_{R}-$ friction force; $F_{G}$ - rotor weight; $F_{\text {magn }}-$ magnetic force generated by the stator pole; $e$ - rotor eccentricity

As a result, the total force of one-sided magnetic attraction, which creates an electromagnetic torque, is determined $[4,6]$ :

$$
\begin{gathered}
\sum F=-F_{G} \sin (\varphi)-F_{R}+\sum F_{y}, \\
F_{R}=\mu_{k} F_{N},
\end{gathered}
$$

where $\mu_{k}$ - friction coefficient.

With all the variety of power steering systems on wheeled rolling stock, the use of the same structural elements and typical schemes is typical. Fig. 5 shows a diagram for calculating the parameters of a power steering system based on a rolling rotor motor.

According to the design scheme, the differential equation for the dynamics of steering wheels on the basis of Newton's second law has the form [7]:

$$
J_{w h} \frac{d^{2} \Theta_{w h}}{d t^{2}}=c_{2} \arcsin \left(\left(\frac{l_{S}+y_{S}}{l_{r}}\right)-\Theta_{w h}\right)-M_{r e s}-M_{t} \operatorname{sgn}\left(\frac{d y_{S}}{d t}\right),
$$

where $J_{w h}$ - moment of inertia of the steered wheels in the horizontal plane, $\mathrm{kg} \cdot \mathrm{m}^{2} ; c_{2}-$ stiffness of the steering wheels, $\mathrm{N} \cdot \mathrm{m} / \mathrm{rad} ; M_{t}-$ moment of friction in the steering gear, $\mathrm{N} \cdot \mathrm{m} ; l_{S}-$ rod length, $\mathrm{m}$; $l_{r}$ - distance from the rod to the swivel arm of the wheel, $\mathrm{m}$; $\Theta_{w h}-$ angle of rotation of the steering wheel, tips; $y_{S}-$ rod displacement, $\mathrm{m}$.

The moment of resistance to turning of the tire $M_{\text {res }}$ reaches about $90 \%$ of the total value on surfaces with a high coefficient of adhesion when the steering wheel is turned in place [8-10]. The decrease in the moment of resistance $M_{\text {res }}$ of turning the tire occurs while driving. This leads to a decrease in the total moment of resistance to turning the steered wheels. 


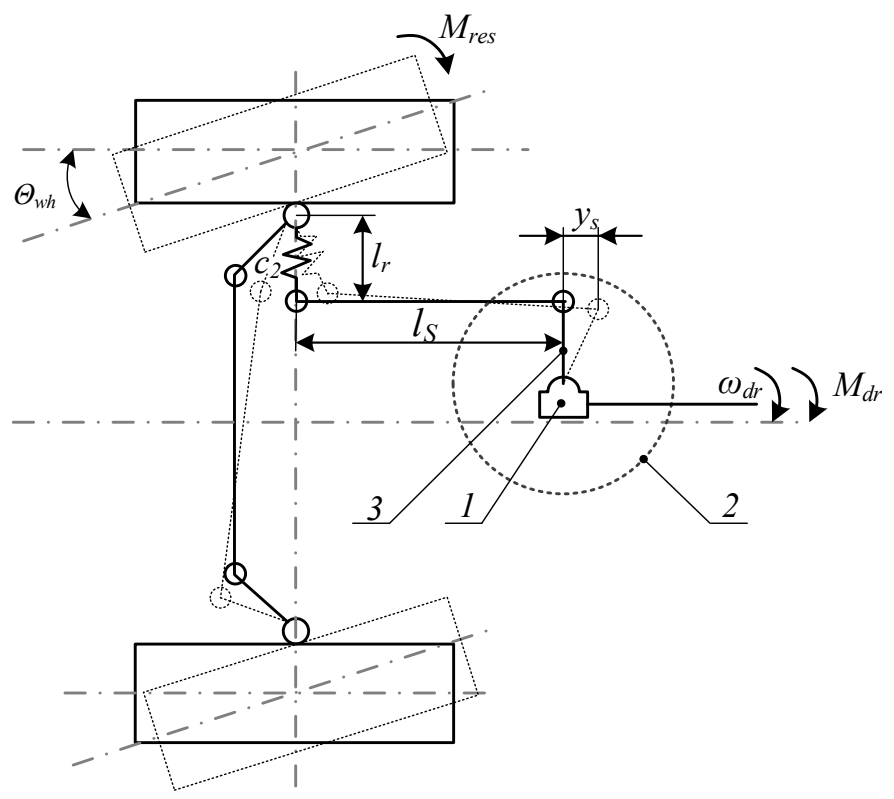

Fig. 5. Diagram of the steering of a trolleybus with a power steering based a rolling rotor motor:

$$
1 \text { - steering gear reducer; } 2 \text { - RRM; } 3 \text { - bipod }
$$

Based on the analysis of works [9-11, 13-21], it was found that the moment of resistance to rotation of the tire depends on the angle of rotation of the controlled wheel, and it is determined:

$$
\left\{\begin{array}{l}
M_{r e s}=c_{\omega} \Theta_{w h}, \quad \Theta_{w h}<5^{\circ}, \\
M_{r e s}=M_{\mu \max }-\left(M_{\mu \max }-c_{\omega} \Theta_{w h}\right)\left(\frac{\Theta_{B}-\Theta_{w h}}{\Theta_{B}-\Theta_{A}}\right)^{2}, 5^{\circ}<\Theta_{w h}<13^{\circ}, \\
M_{r e s}=M_{\mu \max }, \quad \Theta_{w h}>13^{\circ}, \\
M_{\mu \max }=\frac{G_{w h} \cdot \mu}{16 a b}\left[\begin{array}{l}
(a+2 y)\left(b+2 l_{0}\right) \sqrt{(a+2 y)^{2}+\left(b+2 l_{0}\right)^{2}}+ \\
+(a-2 y)\left(b+2 l_{0}\right) \sqrt{(a-2 y)^{2}+\left(b+2 l_{0}\right)^{2}}+ \\
+(a+2 y)\left(b-2 l_{0}\right) \sqrt{(a+2 y)^{2}+\left(b-2 l_{0}\right)^{2}}+ \\
+(a-2 y)\left(b-2 l_{0}\right) \sqrt{(a-2 y)^{2}+\left(b-2 l_{0}\right)^{2}}
\end{array}\right], \\
c_{\omega}=k G_{w h} \cdot 10^{-3}, \\
l_{0}=l_{z}-r_{w h} \cdot \operatorname{tg}\left(\alpha_{k}+\gamma_{k 0}\right), \\
y=r_{w h} \cdot \operatorname{tg} \beta_{k},
\end{array}\right.
$$

where $c_{\omega}$ - angular stiffness of the tire, N.m/deg; $G_{w h}-$ load on the driven wheel, N; $k$ - determined in the range $9 . .11[9,12] ; M_{\mu \max }$ - limiting moment of resistance to tire turn after adhesion; $\Theta_{A}$ - maximum angle of rotation of the wheel on a linear section, $\Theta_{A}=5^{\circ} ; \Theta_{B}$ - minimum angle of rotation of the wheel in the section with maximum adhesion, $\Theta_{B}=13^{\circ} ; \mu$-adhesion coefficient of the tire to the contacts; $a, b$ - sides of the reduced equal-sized rectangle of the tire contact print with contacts, $\mathrm{m} ; y$-stabilization arm, $\mathrm{m} ; l_{o}$ - run-in shoulder, $\mathrm{m} ; l_{z}$-trunnion length, $\mathrm{m} ; r_{w h}-$ steering wheel radius, $\mathrm{m} ; \alpha_{k}$ - angle of the lateral inclination of the king pin, rad; $\gamma_{k 0}-$ steering wheel camber angle, rad; $\beta_{k}$ - angle of the longitudinal inclination of the king pin, rad.

In the steering circuit (Fig. 5) there are elements that characterize the rigidity of the steering wheels. Therefore, the trolleybus steering system should be considered as dual-mass.

In the general case, the equilibrium equation of a mechanical subsystem with two degrees of freedom is characterized by the following system of equations [13]: 


$$
\left\{\begin{array}{l}
J_{1} \frac{d \omega_{1}}{d t}=M_{e}-M_{y}, \\
J_{2} \frac{d \omega_{2}}{d t}=M_{y}-M_{r e s}, \\
M_{y}=C_{12} \int\left(\omega_{1}-\omega_{2}\right) \mathrm{d} t,
\end{array}\right.
$$

where $M_{y}$ - moment of elastic forces, $\mathrm{N} \cdot \mathrm{m} ; J_{1}, J_{2}$ - respectively the moments of inertia of the first and second mass; $C_{12}$ - reduced stiffness coefficient, $\mathrm{N} \cdot \mathrm{m} / \mathrm{rad} ; \omega_{1}, \omega_{2}-$ angular speed of the first and second mass, respectively.

Based on expression (18), the final equation of the mechanical subsystem of the trolleybus steering system based on a rolling rotor motor has the form:

$$
\left\{\begin{array}{l}
J_{R} \frac{d \omega_{R}}{d t}=M_{e}+M_{d r}-M_{y}, \\
J_{w h} \frac{d^{2} \Theta_{w h}}{d t^{2}}=M_{y}-M_{r e s}-M_{t} \operatorname{sgn}\left(\frac{d y_{S}}{d t}\right) \\
M_{y}=c_{2} \arcsin \left(\left(\frac{l_{S}+y_{S}}{l_{r}}\right)-\Theta_{w h}\right) \int\left(\omega_{R}-\omega_{w h}\right) \mathrm{d} t
\end{array}\right.
$$

where $M_{d r}-$ moment that the driver creates when the steering wheel rotates, $\mathrm{N} \cdot \mathrm{m}$.

Based on equation (19), a functional diagram of the mechanical subsystem is drawn up, which is shown in Fig. 6.

Thus, the mathematical model of the steering of a trolleybus with a power steering based on a rolling rotor motor takes the form:

$$
\left\{\begin{array}{l}
u_{n}=i_{n} R_{n}+\frac{d i_{n}}{d t} \cdot L_{\partial n}+K_{E n} \cdot \omega_{R}, \\
J_{R} \frac{d \omega_{R}}{d t}=M_{e}+M_{d r}-M_{y} \\
J_{w h} \frac{d^{2} \Theta_{w h}}{d t^{2}}=M_{y}-M_{r e s}-M_{t} \operatorname{sgn}\left(\frac{d y_{S}}{d t}\right) \\
M_{y}=c_{2} \arcsin \left(\left(\frac{l_{S}+y_{S}}{l_{r}}\right)-\Theta_{w h}\right) \int\left(\omega_{R}-\omega_{w h}\right) \mathrm{d} t \\
L_{\partial n}=L_{(i, \varphi) n}+i_{n} \cdot \frac{\partial L_{(i, \varphi) n}}{\partial i_{n}} \\
K_{E n}=\frac{\partial L_{(i, \varphi) n}}{\partial \varphi} \cdot i_{n}, \\
M_{e}=\sum F \cdot R_{R e x t} .
\end{array}\right.
$$

As a result of research on the basis of differential equations of the electrical and mechanical parts, as well as algebraic equations characterizing the electromagnetic connections of an electric booster drive based on a rolling rotor motor, a mathematical model of trolleybus steering has been developed.

On the basis of the system of equations (20) in the Matlab Simulink environment, a simulation model of the design of the trolleybus steering with an electric power steering is built (Fig. 7).

Rolling rotor motor has the following parameters: outer rotor radius $R_{\text {Rext }}-699.5 \mathrm{~mm}$; stator inner diameter $-700 \mathrm{~mm}$; stator winding resistance $R_{n}-40 \mathrm{Ohm}$; number of stator poles $n-20$.

For each stator pole, a two-dimensional field model of the magnetic system was calculated using the FEMM software package. As a result, the characteristics of flux linkage (Fig. 8) were obtained with respect to the winding current and the position of the rotor. 


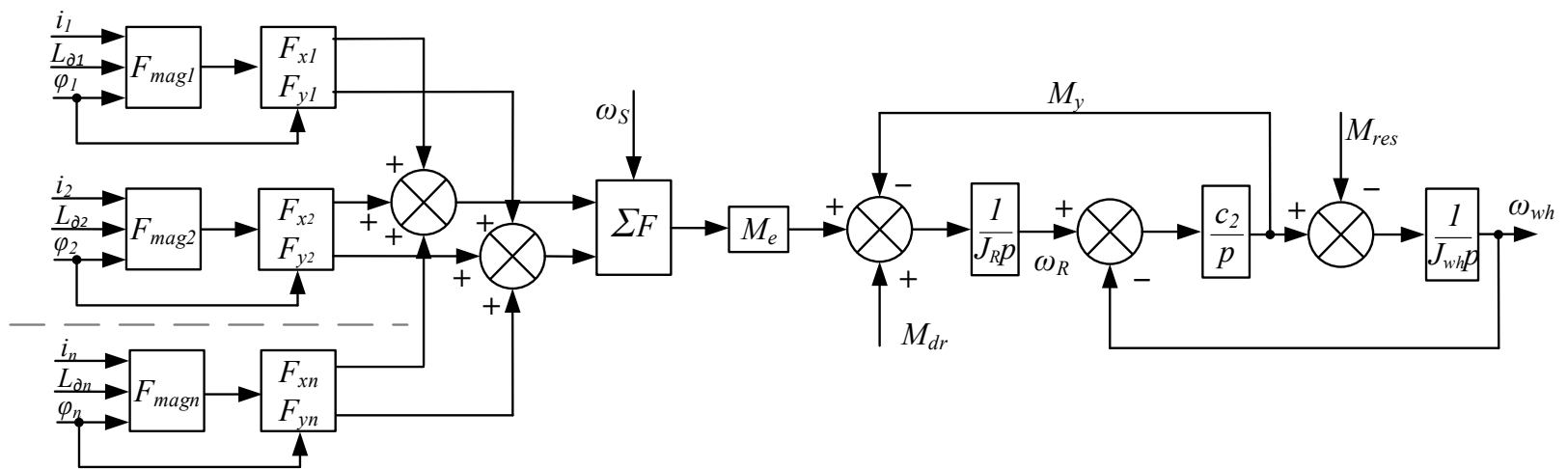

Fig. 6. Functional diagram of the mechanical subsystem of steering based on a rolling rotor motor

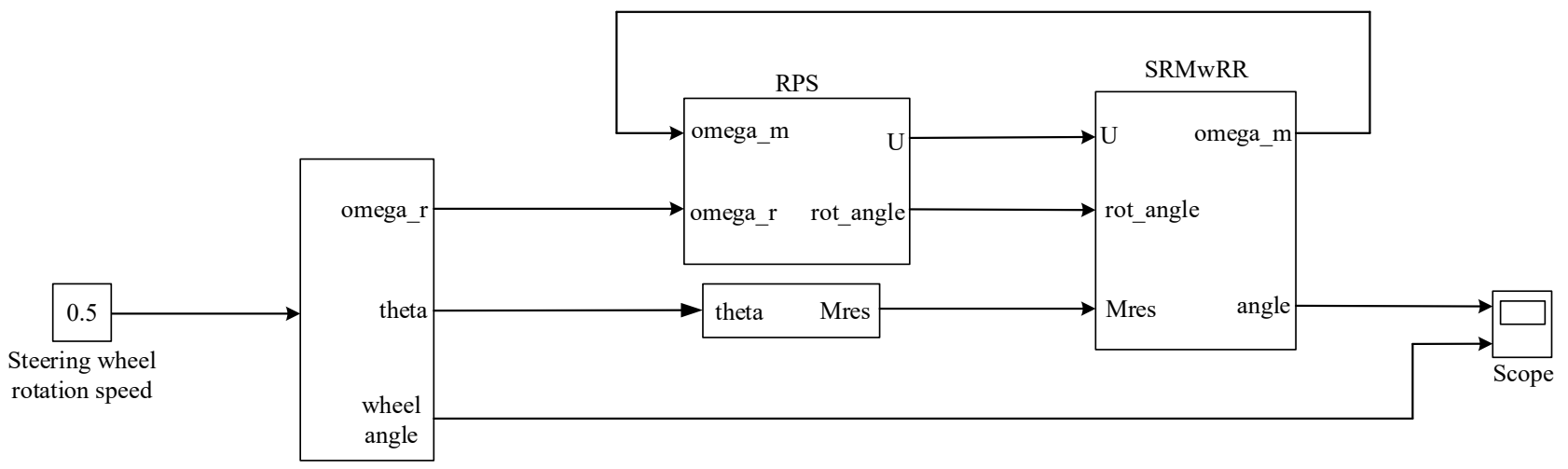

Fig. 7. Simulation model of the electric power steering system
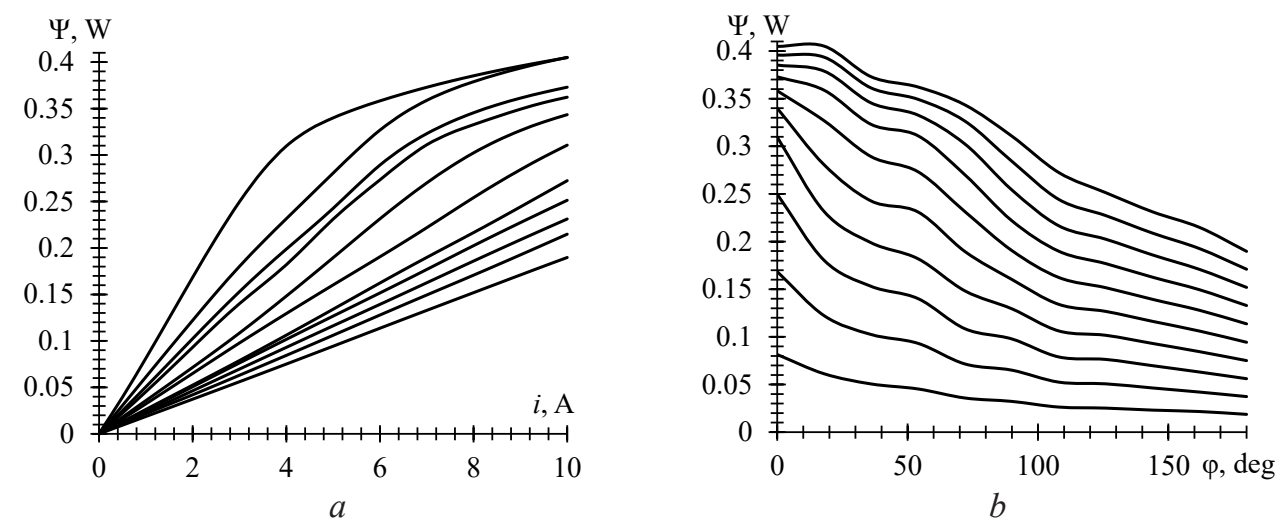

Fig. 8. Characteristic of the flux linkage of the motor pole with the rolling rotor: $a-$ as a function of current; $b-$ as a function of rotation angle

Based on the system of equations (17) and the technical parameters of the trolleybus LAZ E183D1 [9], the dependence (Fig. 9) of the moment of resistance to turning the tire on the steering angle at the maximum permissible axle load $G_{w h}$ was obtained.

Modeling is carried out according to the following initial conditions: steering wheel rotation speed $-1.5 \mathrm{rev} / \mathrm{s}$; power supply voltage of the electric amplifier motor $-400 \mathrm{~V}$ DC. The steering wheels are turned on the spot with the maximum permissible steering axle load. The magnetic systems of each phase of the motor with the rolling rotor are identical. Eddy currents and hysteresis in the magnetic circuit are not taken into account, the active resistances of the phases are level.

Based on the simulation results based on the system of equations (20), the characteristic of the steering wheel rotation angle (Fig. 10) and the characteristic of the moments (Fig. 11) were obtained. 


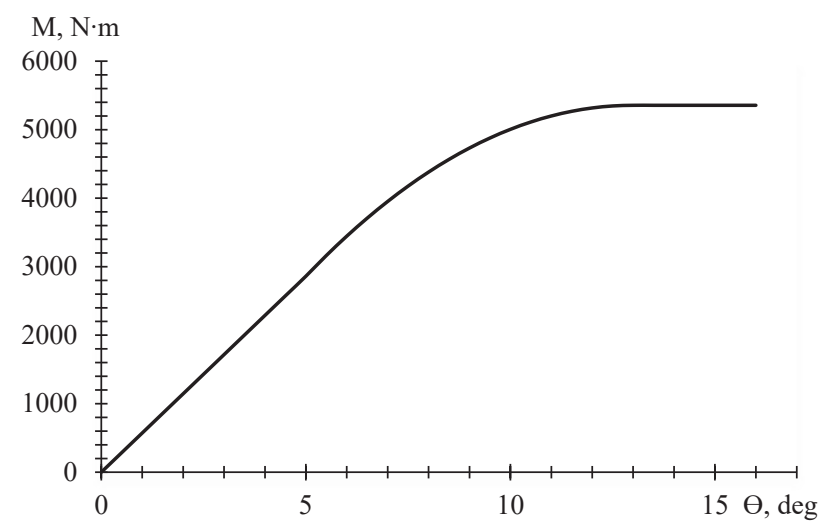

Fig. 9. Dependence of the moment of resistance to turning the tire of the steered wheel in place on the wheel rotation angle

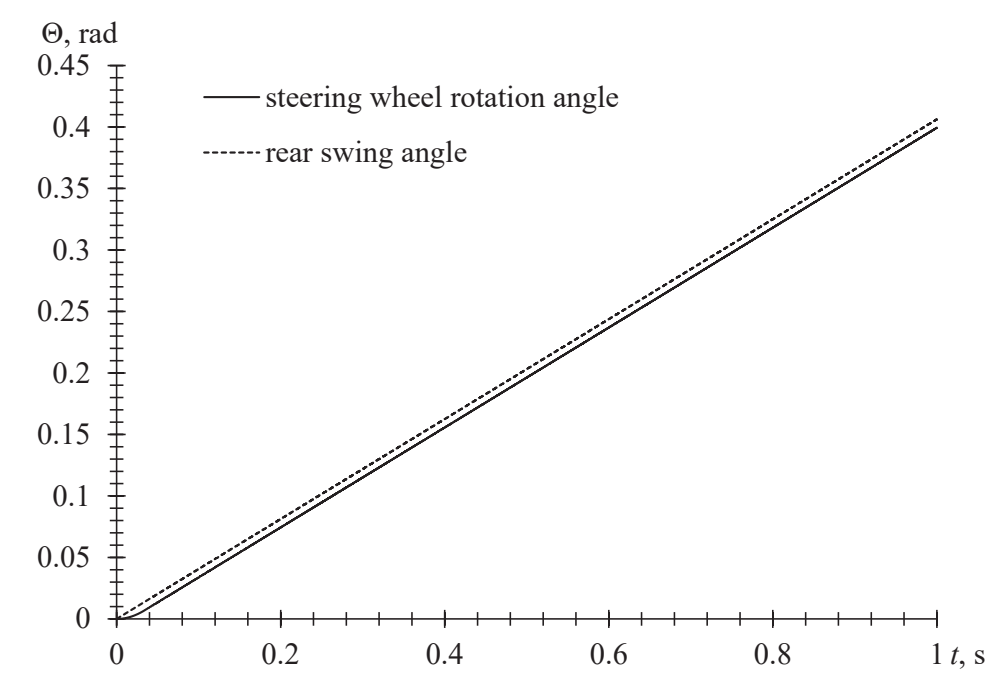

Fig. 10. Characteristic of the steering wheel rotation angle of the trolleybus and the angle of the task with uniform rotation of the steering wheel at a speed of $1.5 \mathrm{rev} / \mathrm{s}$

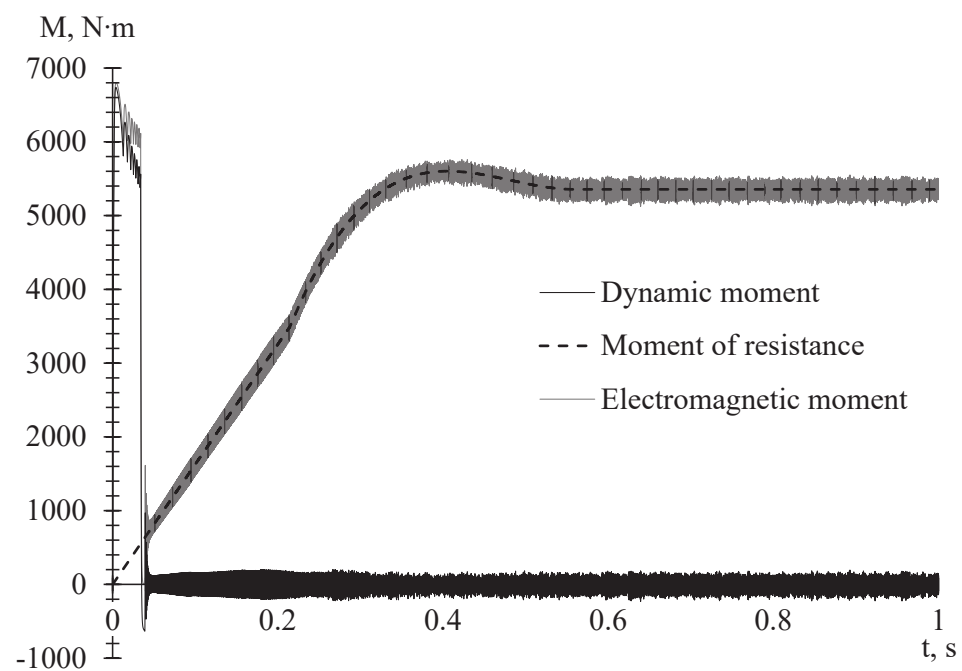

Fig. 11. Characteristic of the moments of the trolleybus steering system with uniform rotation of the steering wheel at a speed of $1.5 \mathrm{rev} / \mathrm{s}$

Analysis of the obtained dependencies shows that due to the moment of inertia, the electric power steering (represented in operation by a rolling rotor motor) reaches the output shaft speed, 
which is equivalent to turning the steering wheel at a speed of $1.5 \mathrm{rev} / \mathrm{s}$. The results were obtained when turning the steering wheels in place and the maximum permissible load on the steering axle for a time of $35 \mathrm{~ms}$. In this case, the angle of rotation of the steered wheels lags behind the angle of rotation of the task. The positioning error $\Delta \Theta$ is $0.01 \mathrm{rad}$. Decreasing the speed of rotation of the steering wheel increases the positioning accuracy of the steered wheels relative to the angle of rotation of the task.

\section{Discussion of the research results of the trolleybus steering system and the development of a mathematical model}

On the basis of the research results and the performed calculations, an innovative technical solution was proposed for a trolleybus steering system using an electric power steering based on a rolling rotor electric motor (Fig. 6).

The mathematical model is proposed (20), which allows analyzing the parameters of the steering system of a trolleybus with an electric power steering. The peculiarity of the mathematical model is that a rolling rotor electric motor is used as an electric power steering.

Thus, based on (20) in the Matlab Simulink environment, a simulation model of a trolleybus steering system with an electric power steering was built (Fig. 7). The resulting model is working. This has been proven experimentally (Fig. 8-11) and the conditions for ensuring its adequacy and practical application in the trolleybus operation.

The proposed mathematical model (20) is intended primarily for the study of dynamic processes in the steering of a trolleybus using an electric power steering based on a rolling rotor electric motor while turning the steering wheels in place. The work does not take into account a number of factors; according to the research results, they have little effect on the value of the resultant moment of resistance when turning the control wheels.

Further development of the mathematical model of trolleybus steering with the use of an electric power steering based on a rolling rotor electric motor is the introduction into the system of equations of dependencies that take into account the effect of the vehicle speed on the resulting moment of resistance when turning the steering wheels.

\section{Conclusions}

A mathematical model has been developed (20), which makes it possible to analyze the steering system of a trolleybus based on a rolling rotor motor in various conditions of its movement, as well as to assess the control effect of electrical and mechanical parameters on the operation of the steering system. The obtained mathematical model allows to:

- simulate the dynamic processes that occur in the trolleybus steering system;

- determine the speed of the steering drive;

- carry out and evaluate a comparative analysis of the system on the control action created by the driver, the influence of factors caused by the road surface, the influence of the parameters of individual units and elements of the steering drive on the electromechanical transient processes of the system.

The mathematical model (20) can be used to calculate the electromechanical and electromagnetic parameters of such systems.

\section{References}

[1] Pavlenko, T., Skurikhin, V., Kolotilo, V., Aharkov, I. (2018). Analysis of problems of the trolleybuses steering system and perspectives for their solution. Collection of scientific works of the State University of Infrastructure and Technologies series «Transport Systems and Technologies», 32 (1), 115-125. doi: https://doi.org/10.32703/2617-9040-2018-32-1-115-125

[2] Golubev, V., Zyubin, Yu. Gidravlicheskaya sistema rulevogo upravleniya trolleybusa. Available at: https://findpatent.ru/ patent/214/2144479.html

[3] Zhagal'skiy, V., Puhovoy, A., Fen'ko, A., Savitskiy, A. et. al. Gidravlicheskiy usilitel' rulevogo upravleniya transportnogo sredstva s klapanom vyklyucheniya usilitelya v kraynih polozheniyah. Available at: https://findpatent.ru/patent/211/2116924.html

[4] Franke, M. (2012). Multidisziplinäre modellierung und simulation eines rolling rotor switched reluktanz antriebes. Erlangung des akademischen Grades Doktoringenieur der Otto-von-Guericke-Universität Magdeburg, 152. 
[5] Polonevich, P. V. (2017). Vozmozhnosti primeneniya i uluchsheniya dvigateley s katyaschimsya rotorom. Aktual'nye problemy energetiki: materialy 73-y nauchno-tekhnicheskoy konferentsii studentov i aspirantov. Minsk: BNTU, 477-479.

[6] Naniy, V. V., Dunev, A. A. (2013). Dependence of the rotation torque from the real load angle of motor with a rolling rotor. Elektrika, 3, 9-12.

[7] Franke, M., Brutscheck, M., Schmucker, U. (2009). Modeling and simulation of a rolling rotor switched reluctance motor. 2009 32nd International Spring Seminar on Electronics Technology. doi: https://doi.org/10.1109/isse.2009.5207002

[8] Klimov, E. (2014). Determination of the moment of steerable wheel tire turning resistance. Naukovi notatky, 46, $246-251$.

[9] Troleibus E183D1-01. Kerivnytstvo z ekspluatatsiyi (2006). Lviv.

[10] Yashchenko, D. (2011). Do vyznachennia momentiv, shcho diyut na keruiuchyi kolisnyi modul avtomobilia. Upravlinnia proektamy, systemnyi analiz i lohistyka. Tekhnichna seriya, 8, 229-234.

[11] Aharkov, I. (2020). Determination of mechanical parameters of electric power steering of the trolleybus steering system. Collection of Scientific Works of the State University of Infrastructure and Technologies Series «Transport Systems and Technologies», 35, 52-59. doi: https://doi.org/10.32703/2617-9040-2020-35-6

[12] Soltus, A., Klimov, E. (2012). The study of moment of tire turning resistance depending on knucle length. Visnyk Kremenchutskoho natsionalnoho universytetu imeni Mykhaila Ostrohradskoho, 4, 88-93.

[13] Zadorozhnyaya, I., Zadorozhniy, N. (2014). Analysis of features of automatic control dual mass electric parameters in the synthesis based on standard characteristic polynomial. Electrical Engineering and Power Engineering, 2, 54-58. doi: https://doi.org/ 10.15588/1607-6761-2014-2-7

[14] Arkkio, A., Biernat, A., Bucki, B., Kaminski, G., Smak, A., Staszewski, P., (2008). Simulation model and laboratory test of switched reluctance motor with rolling rotor. Prace Naukowe Instytutu Maszyn, Napędów i Pomiarów Elektrycznych Politechniki Wrocławskiej, 28, 52-58.

[15] Eyhab, E.-K. (2006). Design and Analysis of Rolled Rotor Switched Reluctance Motor. Journal of Electrical Engineering and Technology, 1 (4), 472-481. doi: https://doi.org/10.5370/jeet.2006.1.4.472

[16] Luczak, D. (2014). Mathematical model of multi-mass electric drive system with flexible connection. 2014 19th International Conference on Methods and Models in Automation and Robotics (MMAR). doi: https://doi.org/10.1109/mmar.2014.6957420

[17] Beloousov, B., Ksenevich, T. I., Vantsevich, V. (2013). Load Estimation of an Open-Link Locomotion Module for Robotic and Commercial Multi-Wheel Applications. SAE International Journal of Commercial Vehicles, 6 (2), 301-307. doi: https://doi.org/ 10.4271/2013-01-2358

[18] Marinescu, G. C., Dumitru, N., Geonea, I. (2012). Dynamic Modelling and Simulation of an Auto Vehicle Steering Mechanism Considering its Elements as Flexible. Applied Mechanics and Materials, 245, 150-155. doi: https://doi.org/10.4028/ www.scientific.net/amm.245.150

[19] Hailu, H. N., Redda, D. T. (2020). Design and Fatigue Analysis of an E-Drive Transmission System of Single-Speed Gear for Electric Vehicle. International Journal of Engineering Research in Africa, 48, 92-107. doi: https://doi.org/10.4028/ www.scientific.net/jera.48.92

[20] Truong, V. T., Hwang, Y. L., Cheng, J. K., Tran, K. D. (2020). Dynamics Analysis and Numerical Simulation of Large-Scale Hydraulic Cylinder Actuators. Applied Mechanics and Materials, 900, 14-19. doi: https://oi.org/10.4028/www.scientific.net/ amm.900.14

[21] Khanh, P. Q., Anh, H. P. H., Kien, C. V. (2019). Advanced Sensor-Less Control of IPMSM Motor Using Adaptive Neural FOC Approach. Applied Mechanics and Materials, 894, 149-157. doi: https://doi.org/10.4028/www.scientific.net/amm.894.149

How to cite: Pavlenko, T., Petrenko, O., Shavkun, V., Aharkov, I. (2021). Development of a mathematical model of the trolleybus steering system using a rolling rotor switched reluctance motor. EUREKA: Physics and Engineering, 4, 63-75. doi: https://doi.org/ $10.21303 / 2461-4262.2021 .001938$ 